Neel, M. C., J. Ross-Ibarra and N. C. Ellstrand (2001): Implication of mating patterns for conservation or the endangered plant Eriogonoum ovalifolium var. vineum (Polygonaceae). American Journal of Botany 88: 1214-1222.

Poenlman, J. M. (1983): 'Breeding Field Crops.' The AVI Publishing Company Inc.: Westport, Connecticut.

Potts, B. M., R. C. Barbour, A. B. Hingston and R. E. VAILLANCOURT (2003): Genetic pollution of native Eucalypt gene pools - identifying the risks. Australian Journal of Botany 51: 1-25.

RitLAND, K. (2002): Extensions of models for the estimation of mating systems using $\mathrm{n}$ independent loci. Heredity 88: 221-228.

SAmpson, J. F., S. D. Hopper and S. H. JAmes (1989): The mating system and population genetic structure in a bird-pollinated mallee, Eucalyptus rhodantha. Heredity 63: 383-393.

SedGley, M. (1989): Acacia. In: 'Handbook of Flowering'. (Ed. A. H. Halevy) pp. 1-11. CRC Press: Boca Raton, Florida.
Simmonds, N. W. and J. SMARTT (1999): 'Principles of Crop Improvement.' Blackwell Science Ltd.: Carlton, Victoria.

Stone, G. N., N. E. Raine, M. Prescott and P. G. WILLMER (2003) Pollination ecology of acacias (Fabaceae, Mimosoideae). Australian Systematic Botany 16: 103-118.

Templeton, A. R. (1986): Coadaptation and outbreeding depression. In: 'Conservation Biology. The Science of Scarcity and Diversity’. (Ed. M. E. Soule) pp. 105-116. Sinauer Associates Inc, Sunderland.

TIOA (1991): 'The Insects of Australia.' (Melbourne University Press: Carlton, Victoria).

WeIR, B. S. (1990): ‘Genetic Data Analysis.' Sinauer Associates Inc.: Sunderland.

YeH, F. C., H.-Y. YANG, B. J. Boyle, Z.-H. Ye and J. X. MAO (1997): POPGENE, the user-friendly shareware for population genetic analysis. Molecular Biology and Biotechnology Centre, University of Alberta: Canada.

ZEIDLER, M. (2000): Electrophoretic analysis of plant isozymes. Biologica 38: 7-16.

\title{
Genetics of Shrinkage in Juvenile Trees of Pinus radiata D. Don From Two Test Sites in Australia
}

\author{
By W. J. Gapare $\left.{ }^{*}\right), 1$, M. Ivković(1), M. B. Powell ${ }^{2)}$, T. A. $\mathrm{MCRAE}^{2)}$ and H. X. Wu ${ }^{1)}$
}

(Received $22^{\text {th }}$ November 2006)

\begin{abstract}
To examine the genetic control of wood shrinkage (radial, tangential and longitudinal) in juvenile wood of radiata pine (Pinus radiata D. Don), we assessed samples collected at breast height in two related progeny tests of age 8 and 9 years, established at two different sites in Australia. Green to oven-dry tangential and radial shrinkage for the outer-rings was similar at both sites. Similarly, mean longitudinal shrinkage for the outer-rings was similar at both sites $(0.3 \%$, ranging from 0.1 to 1.9 at Flynn and $0.4 \%$, ranging from 0.02 to 1.6 , at Kromelite). Mean longitudinal shrinkage for the inner-rings was 4 times greater than that of the outerrings at both sites. The magnitude of the gradient of longitudinal shrinkage from pith to bark (0.001 to $2.9 \%)$ is large enough to cause distortion problems including twist and warp, during drying of sawn boards. These values also suggest that shrinkage in the juvenile core of radiata pine is of major economic importance and therefore should be improved either through genetics or silviculture.
\end{abstract}

1) Ensis ${ }^{3)}$, CSIRO Forestry and Forest Products, P. O. Box E4008, Canberra, ACT 2604, Australia.

2) Southern Tree Breeding Association Inc, P. O. Box 1811 Mt. Gambier, SA 5290, Australia.

3) Ensis is a joint venture between CSIRO FFP P/L and Scion Australasia P/L.

*) Corresponding author: Washington.Gapare@ensisj.com.
Individual-tree narrow-sense individual heritability for tangential and radial shrinkage in the outer-rings (4-6) was moderate at Flynn $(0.24 \pm 0.09$ and $0.26 \pm 0.07$, respectively). There was a lack of significant genetic variation for longitudinal shrinkage in the outer-rings but significant genetic control for the inner-rings (1-2) $\left(h^{2}=0.26 \pm 0.07\right)$. More samples per family are required to detect significant genetic variation for shrinkage traits than other traits due to higher background variation in sampling and measuring shrinkage traits relative to other wood quality traits such as density, microfibril angle (MfA), spiral grain and modulus of elasticity (MoE).

Key words: Pinus radiata, juvenile wood, distortion, shrinkage, genetic control.

\section{Introduction}

Extensive literature is available on the occurrence and limitations of juvenile wood in fast growing conifers, including Pinus radiata D. Don (e.g., Cown et al., 1992; ZoBel and SPRAGUE, 1998; Cown and VAN WYK, 2004). In radiata pine, most of the literature deals with genetic variation in wood density components (e.g., ring density, ring width, earlywood density, latewood density, modulus of elasticity $(\mathrm{MoE})$ ) with tree age (KUMAR and LEE, 2002; KuMAR, 2004; Li and WU, 2005; Wu et al., 2007). Such information may be insufficient for making practi- 
cal assessments of dimensional stability for solid-sawn timber products and structural wood-based composites from juvenile wood (MEGRAW et al., 1998; PERSTORPER et al., 2001; JOHANSSON, 2003). LINDSTRÖM et al. (2004) suggested that tree breeding could provide a long-term solution to improve stiffness as well as drying distortion of construction lumber. Assessing the degree and structure of genetic variation for each wood quality trait in the juvenile core that has a bearing on shape stability is likely to give a better understanding of the relationship between dimensional stability and wood properties.

Shrinkage is the reduction in dimensions of timber during drying due to the movement of moisture out of cell walls of the wood. Wood shrinks differently in all directions (radially, tangentially, and longitudinally). Because wood is anisotropic, it normally shrinks about twice as much tangentially as radially, and shrinks by a very small amount longitudinally (Cown et al., 1991). For example, SKAAR (1988) and HUANG et al. (2003) reported oven-dry shrinkage values of conifers in the following ranges: tangential 5 to $10 \%$, radial 2 to $6 \%$; and longitudinal 0.1 to $0.3 \%$. For radiata pine, the average shrinkage from green to $12 \%$ moisture content was reported to be $4.2 \%$ in the tangential direction, $2 \%$ in the radial direction, and $0.02 \%$ in the longitudinal direction (Cown and McConchie, 1980).

Radial shrinkage occurs perpendicular to the growth rings, while tangential shrinkage occurs in the direction parallel to the growth rings. Tangential shrinkage is always larger than the shrinkage in the radial direction because of cell geometry, wall thickness and orientations of microfibrils in wall layers, and possibly because radial shrinkage is partly restrained by rays that run perpendicular to the growth rings (e.g., NAVI et al., 1995). Transverse shrinkage in the first few juvenile rings is usually less than in mature wood and it may not be critical for the stability of sawn timber (JugO ILIC Pers. Comm.). On the other hand, longitudinal shrinkage is a cause of dimensional instability frequently associated with juvenile wood (LARSON et al., 2001). Although longitudinal shrinkage may be apparently small, for the utilization of timber, only a small variation in the longitudinal shrinkage is enough to cause bow and spring after drying (e.g., JoHANsson, 2002). Transverse (radial and tangential) and longitudinal shrinkage is known to increase rapidly within the first few growth rings from the pith (e.g., Cown et al., 1991). Such gradients within timber pieces, particularly for longitudinal shrinkage, can themselves be detrimental for wood products (e.g., Mishoro and BOOKER, 1988).

Most of the studies on shrinkage of wood have investigated the cause and effect of various wood quality traits (HARRIS and MEYlan, 1965; YING et al., 1994; MEGRAW et al., 1998; Perstorper et al., 2001; PliURA et al., 2005). Very few studies have investigated the inheritance of shrinkage. Shrinkage is said to vary from species to species, and even within any one species, considerable variation is found due to such inherent factors as structure and density (GREENHILL, 1940). NiCHOLLS et al. (1964) reported non-significant heritability for longitudinal shrinkage of radiata pine wood formed at about 10 years. Koshy and LESTER (1994) investigated genetic variation of wood shrinkage in Douglas-fir and reported minimal genetic effects for shrinkage, except for longitudinal shrinkage at ring positions 1 and 2 . This study is unique in that there have been no previous studies that have investigated the inheritance of shrinkage in the juvenile core of radiata pine.

The work described in this paper forms part of a larger study to improve juvenile wood properties in radiata pine (BALTUNis et al., 2007; GAPARE et al., 2006a and b; Matheson et al., submitted). The specific objective of the study was to investigate whether shrinkage in juvenile wood of radiata pine shows exploitable genetic variation relevant to utilization of solid wood products.

\section{Materials and Methods}

The study was based on two progeny trials: BR9611, located at Flynn (latitude $38^{\circ} 14^{\prime} \mathrm{S}$; longitude $146^{\circ} 45^{\prime} \mathrm{E}$ ), Victoria and managed by Hancock Victorian Plantations, and BR9705, located at Kromelite (latitude $37^{\circ} 50^{\prime}$ S; longitude $140^{\circ} 55^{\prime} \mathrm{E}$ ), South Australia and managed by Green Triangle Forest Products. Both sites were initially prepared by ploughing followed by mounding, and soil drainage was considered good. Site and sampling details are presented in Table 1. Trial maintenance at Flynn included a fertilizer application (N: P: K) at a rate of $347 \mathrm{~kg} / \mathrm{ha}$ in 2000 , followed by another aerial fertiliser application at a rate of $329 \mathrm{~kg} / \mathrm{ha}$ in 2003 . Trial maintenance at Kromelite included herbicide application in the first two years of growth aimed at complete weed control. Unlike at Flynn, there was no fertiliser application.

Flynn was planted in June, 1996 with 250 families, consisting of 88 polycross families, 157 full-sib families, and 5 controls, planted in a $10 \times 25$ row-column experimental design (see WiLLIAMs et al., 2002) with 5 blocks and four-tree row plots. Kromelite was planted in July, 1997 with 110 families, consisting of 70 polycross families, 40 full-sib families with no controls, planted in a $10 \times 11$ row-column design with 5 blocks and four-tree row plots. There were 41 parents and only 16 full-sib families common to both sites. Each parent was involved in several crosses. The trees sampled in the study were selected, and approximately $0.5 \mathrm{~m}$ stem billets were cut at breast height in September 2004. At Flynn, two trees out of four per plot were sampled in blocks 1 and 4 . At Kromelite, three trees out of four per plot in blocks 1, 2 and 3 were sampled. In total, 466 trees at Flynn and 308 trees at Kromelite were used in the analyses.

\section{Sample preparation}

After field collection, the billets of samples were stored in a refrigerated room at 4 degrees Celsius to reduce fungal (blue stain) infection. Boards of $30 \mathrm{~mm}$ thickness were cut from the discs with a bandsaw from bark to bark through the pith along the North-South axis. Using a thicknessing machine and a table saw, three sub-samples with dimensions $20 \times 20 \times 150 \mathrm{~mm}$ were taken from three positions of each board (B, C and D) (see Fig. 1). To prevent fungal infection and loss of moisture prior to assessments, the sub-samples were then dipped in sodium hypochlorite (5\% solution), 
Table 1. - Site and sampling details of radiata pine progeny tests sampled for shrinkage analysis.

\begin{tabular}{lll} 
Details & Flynn & Kromelite \\
Experiment number & BR9611 & BR9705 \\
Date planted & $6 / 1996$ & $7 / 1997$ \\
Cambial age at time of sampling & 7 & 6 \\
Spacing & $3.6 \mathrm{~m} \times 2.5 \mathrm{~m}$ & $2.74 \mathrm{~m} \times 2.5 \mathrm{~m}$ \\
Latitude & $38^{\circ} 14^{\prime} \mathrm{S}$ & $37^{\circ} 50^{\circ} \mathrm{S}$ \\
Longitude & $146^{\circ} 45^{\prime} \mathrm{E}$ & $140^{\circ} 55^{\prime} \mathrm{E}$ \\
Elevation (m) & 166 & 55 \\
Annual rainfall (mm) & 760 & 900 \\
Soil type & Sandy loam & Sandy clay-loam \\
Site type & $2^{\text {nd }}$ pine rotation & $2^{\text {ndd }}$ pine rotation \\
Number of families & 250 & 110 \\
Number of blocks sampled & 2 & 3 \\
Number of columns within blocks & 25 & 11 \\
Number of rows within a column & 25 & 30 \\
Trees sampled per family & 2 & 3 \\
Number of samples used in analysis & 466 & 308 \\
\hline
\end{tabular}

wrapped with plastic (cling wrap), and covered with calico cloth soaked in sodium hypochlorite inside sealed plastic boxes. The boxes of sub-samples were then returned to the refrigerated room before shrinkage measurements.

\section{Shrinkage measurements}

The procedures for determining shrinkages for the samples were similar to those used by KINGSTON and RISDON (1961), except sample dimensions. The samples were measured initially in a green state and subsequently oven-dried at $103 \pm 2{ }^{\circ} \mathrm{C}$ to determine shrinkage. Moisture content based on oven-dry weight was determined before and after reconditioning. Because samples were generated from juvenile wood, the oven dried material was in many cases distorted. This presented a problem in accurately measuring the length of samples as the curvature present exaggerated the extent of mea-

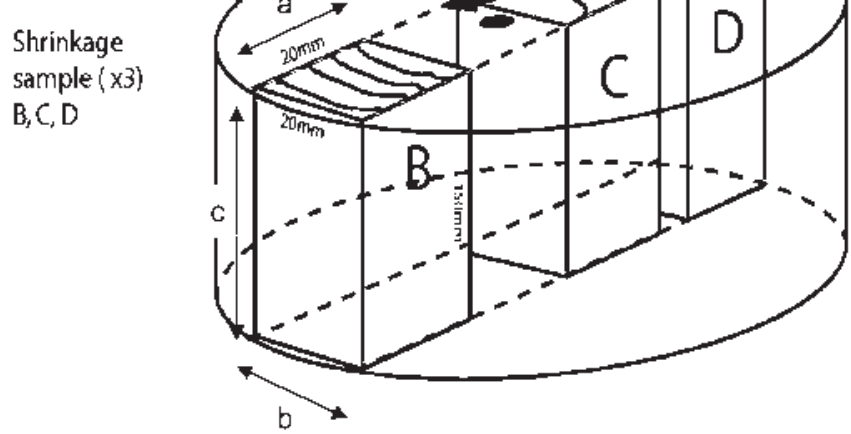

Figure 1. - Schematic position of sub-samples (B, C \& D) taken from three positions on each board.

a) radial shrinkage; b) tangential shrinkage; c) longitudinal shrinkage. sured shrinkage. This necessitated the measurement of the maximum point of curvature and the incorporation of a correction factor to the final length measurement. The maximum curvature was measured by the jig gauge. The gauge was set to zero by a standard bar before a measurement was taken. For each of the three blocks (Fig. 1), radial, tangential and longitudinal dimensions were measured using a digital displacement gauge with readings graduated to $0.001 \mathrm{~mm}$. One measurement was taken in the middle of the sample and subsequently adjusted for distortion and or bow.

The shrinkage value for radial, tangential and longitudinal was expressed as a percentage (\%) of the green measurement. Average values of boards B and D represented the outer-rings (rings 4 to 6 at Flynn; and rings 3 to 5 at Kromelite), whereas $\mathrm{C}$ represented the innerrings (rings 1 and 2) close to the pith. Longitudinal gradient (pith to bark) was defined as the difference in shrinkage between outer and inner-rings. The traits assessed are summarised in Table 2.

\section{Genetic models}

All shrinkage traits were analysed using ASREML (GILMOUR et al., 2005) using an individual tree linear model for each site separately. The mixed linear model was constructed with fixed and random effects. The fixed effects included blocks whereas the random part, which is connected to the genetic model, was constructed with genetic effects, tied to the parents of the full-sib families through a design matrix, and a relationship matrix, derived from the pedigree. No significant variation caused by full-sib family effects after accounting for parental effect or breeding value was detected in preliminary analyses. This means there was no significant dominance variance. Thus the genetic model was based on the equation $P=A+E$, where $P$ is the phenotypic 
Table 2. - Mean estimates of radial, tangential and longitudinal shrinkage estimates of Pinus radiata studied at Flynn and Kromelite sites.

\begin{tabular}{|c|c|c|c|c|c|}
\hline \multirow[b]{2}{*}{$\begin{array}{l}\text { Measured } \\
\text { shrinkage property }\end{array}$} & \multirow[b]{2}{*}{ Abbrev } & \multicolumn{2}{|c|}{ Flynn } & \multicolumn{2}{|c|}{ Kromelite } \\
\hline & & $\begin{array}{c}\text { Mean } \pm \text { s.e. } \\
(\%)^{*}\end{array}$ & $\begin{array}{c}\text { Range } \\
(\%)\end{array}$ & $\begin{array}{c}\text { Mean } \pm \text { s.e. } \\
(\%)^{*}\end{array}$ & $\begin{array}{c}\text { Range } \\
(\%)\end{array}$ \\
\hline Tangential (outer-rings) & TS & $6.1 \pm 0.03^{* *}$ & $3.8-7.9$ & $5.7 \pm 0.04^{* *}$ & $2.9-7.8$ \\
\hline Radial (outer-rings) & RS & $3.6 \pm 0.02^{* *}$ & $1.9-5.2$ & $3.3 \pm 0.03^{* *}$ & $1.6-5.0$ \\
\hline Tangential/Radial Ratio & TRR & $1.7 \pm 0.01^{ \pm *}$ & $1.1-2.6$ & $1.8 \pm 0.02^{\star \star}$ & $0.9-2.9$ \\
\hline Longitudinal (outer-rings) & LSO & $0.3 \pm 0.01^{ \pm *}$ & $0.1-1.9$ & $0.4 \pm 0.02^{* *}$ & $0.02-1.6$ \\
\hline Longitudinal (inmer-rings) & LCl & $1.3 \pm 0.03^{\text {ns }}$ & $0.3-3.3$ & $1.4 \pm 0.03^{\mathrm{ns}}$ & $0.24-3.9$ \\
\hline Longi Gradient (Pith to bark) & LGR & $0.97 \pm 0.01^{\mathrm{ns}}$ & $0.001-2.9$ & $0.87 \pm 0.02^{\mathrm{ns}}$ & $0.02-2.23$ \\
\hline
\end{tabular}

\footnotetext{
* all percent shrinkage values were from green to oven-dry (zero moisture content).

** means for each trait between sites significantly different at $p<0.05$.

ns means for each trait between sites not significantly different at $p<0.05$.
}

value, $A$ is the additive genetic effect, and $E$ the independent environmental effect including the genetic residual. The general linear mixed model used for the analysis was as follows:

$$
y \approx x b+7 a+e
$$

where $y$ is a vector of individual-tree observations, $X$ is an incidence matrix relating observations to fixed effects, $b$ is a vector of fixed block effects (in single-site analyses) or site and block effects (in pooled-site analyses), $Z$ is an incidence matrix relating observations to random effects, $a$ and $e$ are vectors of random individual-tree additive genetic and residual error effects, assumed to be multivariate normally distributed with mean 0 and variances $\mathrm{G}$ and $\mathrm{R}$, respectively, defined by:

$$
\left[\begin{array}{l}
a \\
e
\end{array}\right] \approx N\left(\left[\begin{array}{l}
0 \\
0
\end{array}\right], \quad\left[\begin{array}{cc}
G \sigma^{2}{ }^{2} & 0 \\
0 & R \sigma^{2}{ }
\end{array}\right]\right)
$$

where 0 is the null matrix; $G$ is the numerator relationship matrix, which describes the additive genetic relationships among individual genotypes; $R$ is the residual variance matrix; $\sigma_{a}^{2}$ is the additive genetic variance between individual genotypes, and $\sigma_{\mathrm{e}}^{2}$ is the residual variance.

Given the components of variance estimated under model [1], estimates of heritability for each trait at each trial were obtained as follows:

$$
\mathrm{h}^{2}=\frac{\sigma^{2}{ }^{2}}{\sigma^{2}{ }^{2}+\sigma_{\mathrm{k}}}
$$

in which $\sigma^{2}$, and $\sigma_{\text {e }}^{2}$ represent the additive genetic variance, and residual variance, respectively. The standard errors of $\mathrm{h}^{2}$ i were calculated according to the general expression for the variance of a ratio, based on an approximation using a first-order Taylor series expansion (LYNCH and WALSH, 1998).

\section{Results and Discussion}

\section{Variation of shrinkage traits}

Table 2 presents estimates of average values for tangential, radial, and longitudinal shrinkage, ratio of tangential to radial shrinkage, and the longitudinal gradi- ent from pith to bark at Flynn and Kromelite. Tangential shrinkage (TS) for outer-rings (4 to 6 ) at Flynn averaged $6.1 \%$, ranging from $3.8 \%$ to $7.9 \%$. Similarly, tangential shrinkage (TS) for outer-rings (3 to 5) at Kromelite averaged $5.7 \%$, ranging from $2.9 \%$ to $7.8 \%$. As expected, radial shrinkage (RS) (perpendicular to or across annual rings) for outer-rings at both sites was approximately half that of tangential shrinkage (shrinkage parallel to the annual growth rings). For example, radial shrinkage at Flynn was $3.6 \%$ compared to tangential shrinkage of $6.1 \%$ (2:1 ratio) (Table 2). SHUPE and CHOONG (1995) reported a similar ratio in corewood of Liquidambar styraciflua. Our results also agree with those of Koshy and LESTER (1994) who reported $8.14 \%$ tangential shrinkage and $4.54 \%$ radial shrinkage at ring 5 in Douglas-fir. Shrinkage values for both tangential and radial fall within expected ranges for conifers (5-10\% for tangential; 2-6\% for radial) (e.g., HuANG et al., 2003).

The ratio of tangential to radial shrinkage (TRR) is important because it provides information on the dimensional stability of wood. A low ratio is important where dimensional stability is required (e.g., LOWELL and KRAHMER, 1993). However, due to ring angle caused by the wandering pith inherent in sample C (inner-rings) and to some extent, ring curvature close to the pith; it is generally not possible to distinguish between tangential and radial shrinkage values for the inner-rings close to the pith. This is partly because any shrinkage in samples close to the pith will be a function of both radial and tangential shrinkage. We attempted adjustments for ring curvature following DUMAIL and CASTERA (1997) but this had minimal effects. Therefore, no estimates of either radial or tangential shrinkage are presented in this study for inner-rings (sample C).

Mean values for longitudinal shrinkage (LSO) in outer-rings at Flynn and Kromelite were significantly different (Table 2). These values were found to be slightly greater than expected for most conifers ( 0.1 to $0.3 \%)$, including radiata pine. In addition, average longitudinal shrinkage (LSI) for the inner-rings (1-2) were greater than those of the outer-rings 4 to 6 (LSO) and far exceeded the expected threshold values of 0.1 to $0.3 \%$ at 
both sites. In a study of Douglas-fir, KOSHY and LESTER (1994) found a decreasing pattern in longitudinal shrinkage from pith to bark. PERSTORPER et al. (2001) also found a decreasing trend in longitudinal shrinkage from pith to bark in a fast-grown stand of Norway spruce. Decrease in longitudinal shrinkage from pith to bark has been attributed to the decrease in microfibril angle of the S-2 layer, and grain spirality within the juvenile core zone close to pith (e.g., WALKER and Butterfield, 1996; Bengtsson, 1997; HuAng et al., 2003). Another influence might be the increase in proportion of latewood that is closely connected with the radial decrease in ring width from pith to bark. BALTUNIS et al. (2007) reported a radial decrease in ring width from pith to bark for the same genetic material. Average density was significantly lower at Kromelite than at Flynn and growth rates were greater at Kromelite than at Flynn (BALTUNIS et al., 2007). The Kromelite site was observed to be more uniform, at lower elevation with greater rainfall and a more productive soil (Table 1). In addition, microfibril angle (MfA) in the juvenile core ranged from $17.7^{\circ}$ to $43.1^{\circ}$ at both sites but with higher MfA at Kromelite than at Flynn (BALTUNIS et al., 2006). It has been demonstrated that wood shrinks longitudinally by a significant amount when MfA exceeds 35o (HARRIS and MEYLAN, 1965) and our data suggest the same.

The longitudinal shrinkage values may be relatively small, but they have importance to utilization, and only a small variation in longitudinal shrinkage is enough to make solid wood products unstable and cause warping and twisting in planks after drying (e.g., MEGRAW et al., 1998; JoHANSSON, 2002). The gradient of longitudinal shrinkage from pith to bark, just like that of spiral grain can also be of economical importance in the juvenile core of radiata pine (Mishoro and BookeR, 1988). The magnitude of the gradient observed for longitudinal shrinkage (range 0.001 to $2.9 \%$; mean $0.97 \%$ ) is large enough to cause distortion problems including twist, during drying of sawn boards (e.g., BÄCKstRöM et al., 2006). This suggests that the internal gradient of longitudinal shrinkage from pith to bark within individual boards is important in addition to the magnitude of shrinkage itself.

\section{Heritability estimates}

Individual-tree narrow-sense heritabilities for tangential and radial shrinkage for the outer-rings at Flynn were $0.24 \pm 0.09$ and $0.26 \pm 0.07$, respectively. However, there was a lack of significant genetic variation for longitudinal shrinkage for the outer-rings at Flynn. For the inner-rings, there was moderate individual-tree narrowsense heritability $(0.25 \pm 0.06)$ for longitudinal shrinkage. In addition, there was a high individual narrowsense heritability $(0.48 \pm 0.12)$ for the ratio of tangential to radial shrinkage for the outer-rings. The ratio provides information on the dimensional stability of wood. However, selection for tangential and radial shrinkage reduction is likely to reduce the ratio of the two traits.

Genetic variation for all of the shrinkage traits at Kromelite was observed to be non-significant, despite significant genetic variation at Flynn (Table 3). Previous studies on the same genetic material, BALTUNIS et al. (2007), GAPARE et al. (2006b) and MATHESON et al. (submitted) found significant and exploitable genetic variation for MoE, spiral grain and acoustic time of flight, respectively. For example, MATHESON et al. (submitted) reported a lower heritability for acoustic time of flight at Kromelite $\left(h^{2}=0.44\right)$ than at Flynn $\left(h^{2}=0.67\right)$. Similarly, BALTUNIS et al. (2007) reported lower heritability estimates for $\mathrm{MoE}\left(\mathrm{h}^{2}=0.37\right)$ than at Flynn $\left(\mathrm{h}^{2}=0.69\right)$. This suggests that the genetic variances being estimated are smaller at Kromelite than at Flynn. The heritability estimates for shrinkage traits at Flynn were generally moderate and estimates for Kromelite seem likely to be even lower. Low heritability is sensitive to small sample size per family which probably explains results of BALTUNIS et al. (2007) who also found non-significant genetic variation for increment core length at Kromelite for the same genetic material. We suggest that even though the sample size ( 3 trees per family) at Kromelite was larger than at Flynn (2 trees per family), it was still too small to detect significant genetic variation at Kromelite, even though the number of families was adequate (110 families). To examine this, we used analyses for stem diameter $(\mathrm{DBH})$ where we had data for all 20 trees per family in the same trial. Significant genetic variation was detected when $\mathrm{DBH}$ was analysed using 20 trees per family (unpublished data). However, when we analysed the three trees per family assessed for shrinkage with DBH measurements and estimated variances for $\mathrm{DBH}$, we did not detect any significant genetic variation. This suggests that for traits with lower levels of additive genetic control, larger sample sizes per family are required to detect significant genetic variation. In addition, shrinkage traits usually incur high noise in sampling and measurement processes. We pooled the data from both sites for joint analyses. The joint analyses yielded similar estimates of heritability as from Flynn (Table 3). We therefore concluded that larger sample sizes per family are required for traits with inherently low genetic control.

In contrast to other wood quality traits, there is limited information on heritability estimates for shrinkage traits in conifers. KosHY and LESTER (1994) reported non-significant heritability estimates for both tangential and radial shrinkage for rings 4 and 5 in Douglas-fir. Work by NePVEU and VeLLING (1983) on silver birch showed moderate individual-tree narrow-sense (0.32) and broad-sense (0.38) heritabilities for tangential shrinkage but showed no significant heritabilities for radial shrinkage.

Our findings suggest that heritability for longitudinal shrinkage decreases from pith to bark. We found a lack of significant genetic variation for longitudinal shrinkage for the outer-rings but significant genetic variation for the inner-rings ( 1 to 2 rings) $(0.25 \pm 0.06)$. In a study involving 12 half-sib families of Douglas-fir, KosHY and LESTER (1994) reported a gradual decrease in heritability from pith $\left(\mathrm{h}^{2}=0.39\right)$ to ring position $5\left(\mathrm{~h}^{2}=0\right)$. Studies by NiCHOLLS et al. (1964) showed non-significant heritability for longitudinal shrinkage of wood in radiata pine outer-rings, again reflecting large noise in data for shrinkage traits. 
Table 3. - Estimates of individual-tree narrow-sense heritability for shrinkage traits in Pinus radiata at Flynn and Kromelite.

\begin{tabular}{lllll}
\hline & & & \multicolumn{3}{l}{ Herilability estimale } \\
Measured & Abbrev & Flynn & Kromelite & Joint \\
shrinkage property & & & & \\
Tangential (outer-rings) & TS & $0.24 \pm 0.09$ & 0.00 & $0.26 \pm 0.09$ \\
Radial (outer-rings) & RS & $0.26 \pm 0.07$ & 0.00 & $0.20 \pm 0.08$ \\
Tangential/Radial Ratio & TRR & $0.48 \pm 0.12$ & $0.29 \pm 0.33$ & $0.45 \pm 0.09$ \\
Longitudinal (outer-rings) & LSO & $0.05 \pm 0.08$ & 0.00 & $0.13 \pm 0.08$ \\
Longitudinal (inner-rings) & LCl & $0.25 \pm 0.06$ & 0.00 & $0.20 \pm 0.08$ \\
Longitudinal Gradient (Pith to bark) & LGR & $0.20 \pm 0.11$ & $0.21 \pm 0.30$ & $0.15 \pm 0.07$ \\
\hline
\end{tabular}

As shrinkage traits are related to other wood properties including wood density, spiral grain, microfibril angle, chemical structure and compression wood content and $\mathrm{MoE}$, a change in any of these traits is likely to have an effect on both directional and volumetric shrinkage of wood (e.g., LINDSTRÖM et al., 2005). For example, MfA is one of the major factors that controls $\mathrm{MoE}$ (a major breeding objective for radiata pine breeding in Australia, see Ivković et al. 2006) and is also a predictor of tendency to warp (MYSZEWSKI et al., 2004). For instance, a reduction in MfA and increase in $\mathrm{MoE}$ in the first growth rings should improve the structural and shrinkage properties of wood because a lower MfA and spiral grain in the first growth rings will limit volumetric shrinkage, and therefore, the drying distortion of sawn timber (LiNDSTRÖM et al., 2005). Consequently, a reduction in the pith-to-bark gradient for traits such as MfA and MoE would reduce shrinkage and drying distortion of sawn timber. Therefore, a suitable alternative for dealing with challenges of shrinkage measurements in the juvenile core of fast-grown conifers include breeding for reduced MfA and increased MoE in the juvenile core. ILIC (2004) reported an $\mathrm{R}^{2}$ of 0.90 between longitudinal shrinkage and acoustic velocity in radiata pine. High correlation between sound wave velocity and longitudinal shrinkage makes us of acoustic measurement techniques advantageous for tree improvement.

\section{Conclusions}

We investigated the inheritance of shrinkage in the juvenile core of radiata pine. Our findings have significant implications for breeding efforts to reduce shrinkage in the juvenile core of radiata pine. To our knowledge, this is the largest study investigating the genetic control of shrinkage in conifers conducted to date. The most important results and conclusions were the following:

1. Longitudinal shrinkage values for both inner- and outer-rings exceeded the expected threshold values for most conifers, which suggests that longitudinal shrinkage in the juvenile core of radiata pine is a trait of economic importance and should be improved by genetics or silviculture.

2. There was moderate additive genetic control for radial and tangential shrinkage in the outer-rings and also for longitudinal shrinkage in the inner-rings.
3. More samples are required to study genetic variation for traits that generally have low levels of additive genetic control such as shrinkage traits relative to other wood quality traits such as density, MfA and MoE because of expected higher noise in sampling and measuring shrinkage traits.

4. Understanding the degree to which longitudinal shrinkage is related to other wood quality traits such as MfA, MoE and acoustic sound velocity is important for an indirect measurement of shrinkage or dimensional stability and for indirect selection for tree improvement for shrinkage traits, especially longitudinal shrinkage.

\section{Acknowledgements}

This study was jointly funded by FWPRDC, STBA, and Ensis/CSIRO. We thank several members of Ensis/CSIRO team David Spencer, JoHn Owen and AlJoy Abarquez, who coordinated the field sampling and samples' preparation. Special thanks to our field collaborators - Mike Powell from STBA and PETER BAXTER of Hancock Victoria Plantations. We also thank Dr. Jugo ILIC and ANDREW MoRRow for coordinating the shrinkage measurements. We are also grateful to the critical suggestions made by two reviewers which substantially improved the manuscript.

\section{References}

BÄCKströM, M., and M. JoHANSSON (2006): Analytical model of twist in Norway spruce (Picea abies) timber. Scan. J. For. Res. 21: 54-62.

Baltunis, B., H. X. Wu, and M. B. Powell (2007): Inheritance of density, microfibril angle and modulus of elasticity in the juvenile wood of Pinus radiata. (in press).

Bengtsson, C (1997): Creep in sawn spruce exposed to varying humidity - influence of raw material parameters. Licentiate thesis. Chalmers University of Technology, Gothenburg, Sweden.

Cown, D. J. and D. L. McConchIE (1980): Wood property variations in an old-crop stand in radiata pine. N.Z.J. For. Sci. 10: 508-520.

Cown, D. J., D. L. McConchie and G. D. Young (1991): Radiata Pine Wood Properties Survey. Ministry of Forestry. FRI Bulletin No. 50.

Cown, D. J. and L. VAN WYK (2004): Profitable wood processing - what does it require? Good wood!. N.Z.J. For. 49: $10-14$. 
Cown, D. J., G. D. Young and R. D. BuRdon (1992): Variation in wood characteristics of 20-year old half-sib families of Pinus radiata. N.Z. J. For. Sci. 22: 63-76.

DuMAIL, J.F. and P. CASTERA (1997): Transverse shrinkage in maritime pine juvenile wood. Wood Sci. and Tech 31: 251-264.

Gapare, W. J., H. X. Wu and A. Abarquez (2006a): Genetic control in the time of transition from juvenile wood to mature wood in Pinus radiata D. Don. Annals of Forest Science 63: 871-878.

Gapare, W. J., A. Hathorn, D. Kain, A. C. Matheson and H. X. WU (2006b): Inheritance of spiral grain in the juvenile core of Pinus radiata D. Don. Can. J. For. Res. 37: $116-127$.

Gilmour, A. R., B. J. Gogel, B. R. Cullis and R. ThompSON (2005): ASReml User Guide Release 2.0, VSN International Ltd, Hemel Hempstead HP1 1ES, UK. 315 pp.

GreEnHILL, W. L. (1940): The shrinkage of Australian Timbers Part 2. Shrinkage data for 170 Timbers. Division of Forest Products - Technical paper No. 35.

HARRIS, J. M. and B. A. MEYLAN (1965): The influence of microfibril angle on longitudinal and tangential shrinkage in Pinus radiata. Holzforchung 19: 144-153.

Huang, C. L., H. Lindstrom, R. NAKAda and J. Ralston (2003): Cell wall structure and wood properties determined by acoustics - a selective review. Holz als Rohund Werkstoff 61: 321-335.

ILIC, H (2004): Effect of juvenile core on softwood processing: results from recent resource and wood quality studies. In: Wood quality 2004 - Practical tools and new technologies to improve segregation of logs and lumber for processing. Albury, NSW, 5-6 ${ }^{\text {th }}$ August, 2004.

Ivković, M., H. X. Wu, T. A. McRAe and M. B. Powell (2006): Developing Breeding Objective for Pinus Radiata Pine Structural Wood Production I: Bio-Economic Model and Economic Weights. Can. J. of For. Res 36: 2920-2931.

Johansson, M. (2002): Moisture-induced distortion in Norway spruce timber - experiments and models. PhD Thesis, Chalmers University of Technology, Gothenburg, Sweden.

Johansson, M. (2003): Prediction of bow and crook in timber studs based on variation in longitudinal shrinkage. Wood and Fiber Sci. 35: 445-455.

Kingston, R. S. T. and C. J. E. Risdon (1961): Shrinkage and density of Australian and other south-west Pacific wood. CSIRO Division of Forest Products. Technical Paper No. 13.

Koshy, M. P. and D. T. Lester (1994): Genetic variation of wood shrinkage in a progeny test of coastal Douglas-fir. Can. J. For. Res. 24: 1734-1740.

KumaR, S. (2004): Genetic parameter estimates for wood stiffness, strength, internal checking and resin bleeding for radiata pine. Can. J. of For. Res. 34: 2601-2610.

KuMAR, S. and J. LEE (2002): Age-age correlations and early selection for end-of-rotation wood density in radiata pine. For. Gen 9: 323-330.

Larson, P. R., D. E. Kretschmann, A. Clark III, A. and J. E. IsENBRANDS (2001): Juvenile wood formation and properties in southern pine. General Technical Report. FPL-GTR-129, Madison, WI, U. S. Department of Agriculture, Forest Service, Forest Products Laboratory, $42 \mathrm{p}$.

LI, L. and H. X. WU (2005): Efficiency of early selection for rotation-aged growth and wood density traits in Pinus radiata. Can J. For Res 35: 2019-2029.
Lindström, H., R. Evans and M. ReAle (2005): Implications of selecting tree clones with high modulus of elasticity. N. Z. J. For. Sci. 35: 50-71.

Lindström, H., P. HARRIS, C. T. Sorensson and R. Evans (2004): Stiffness and wood variation of 3-year old Pinus radiata clones. Wood Sci. and Tech 38: 579-597.

LOWELL, E. C. and R. L. KRAHMER (1993): Effects of lean in red alder trees on wood shrinkage and density. Wood and Fiber Sci. 25: 2-7.

LYNCH, M. and B. WALSH (1998): Genetics and analysis of quantitative traits. Sinauer, Sunderland USA.

Matheson, A. C., W. J. Gapare, H. Ilic and H. X. WU: Inheritance and genetic gain in wood stiffness in radiata pine measured acoustically in young standing trees (Submitted).

Megraw, R. A., G. LeAF and D. Bremer (1998): Longitudinal shrinkage and microfibril angle in loblolly pine. Pp. 27-61. In: ButTerfield, B. G., (Ed.) Proceedings of IAWA/IUFRO Workshop on "Microfibril Angle in Wood". University of Canterbury, New Zealand.

Mishoro, A. and R. E. Booker (1988): Warping in new crop Radiata pine 100 x 50 mm (2 by 4 ) boards. Bulletin of the Tokyo University Forests No. 80: 37-68.

Myszewski, J. H., F. E. Bridgewater, W. J. Lowe, T. D. BYram and R. A. MEgraW (2004): Genetic variation in the microfibril angle of loblolly pine from two test sites. South. J. App. For. 28: 196-204.

Navi, P., P. K. Rastogi, V. Greese and A. Tolou (1995): Micromechanics of wood subjected to axial tension. Wood Sci. and Tech 6: 293-301.

NePveu, P. G. and P. Velling (1983): Variabilite genetique individuelle de la qualite du bois chez Betula pendula Roth. Silv. Genet. 32: 37-49.

Nicholls, J. W. P., H. E. DADswell and J. M. Fielding (1964): The heritability of wood characteristics in Pinus radiata. Silvae Genet. 13: 68-71.

Perstorper, R., M. Johansson, R. Kliger and G. JohansSON (2001): Distortion in Norway spruce timber. Part 1. Variation of relevant wood properties. Holz als Roh- und Werkstoff 59: 94-103.

Pliura, A., Q. Yu, S. Y. Zhang, J. Mackay, P. Perinet and J. Bousquet (2005): Variation in wood density and shrinkage and their relationships to growth of selected young poplar hybrid crosses. For. Sci. 51: 472-482.

Shupe, T. F. and E. T. Choong (1995): Shrinkage of outerwood, middle wood and corewood of two sweetgum trees. Wood and Fiber Science 27: 384-388.

SkAAR, C. (1988): Wood-Water Relations. Springer-Verlag, Berlin-Heidelberg-New York. 283pp (1988).

WALKeR, J. C. F. and B. G. ButTERFIELD (1996): The importance of microfibril angle for the processing industries. N. Z. J. For. 40: 34-40.

Williams, E., A. C. Matheson and C. E. Harwood (2002): Experimental Design and Analysis for Tree Improvement. $2^{\text {nd }}$ Edition CSIRO Publishing. $214 \mathrm{pp}$.

Wu, H. X., M. B. Powell, J. L. YANG, M. Ivković and T. A. McRAE (2007): Efficiency of early selection for rotation-aged wood quality traits in radiata pine. Annals of Forest Science 64: 1-9.

Ying, L., D. E. Kretschmann and B. A. Bendtsen (1994): Longitudinal shrinkage in fast-grown loblolly pine plantation wood. For. Prod. Journal 44: 58-62.

Zobel, B. J. and J. R. Sprague, J. (1998): Juvenile wood in forest trees. Springer-Verlag, Berlin, Germany. $300 \mathrm{pp}$. 